\title{
Characterization and Evolution of a Digital Economy Ecosystem Based on an Interspecies Competition Model
}

\author{
Han Zhou (iD, Xiaorui Han, and Le Wang \\ Economics and Trade College, Hebei Finance University, Baoding, Hebei 071000, China \\ Correspondence should be addressed to Han Zhou; zhouhan@hbfu.edu.cn
}

Received 13 November 2021; Accepted 17 December 2021; Published 4 January 2022

Academic Editor: Miaochao Chen

Copyright ( $\odot 2022$ Han Zhou et al. This is an open access article distributed under the Creative Commons Attribution License, which permits unrestricted use, distribution, and reproduction in any medium, provided the original work is properly cited.

\begin{abstract}
This paper provides an in-depth study and analysis of the characterization of the digital economy ecosystem and the mechanism of eye-flowering through the method of interspecies competition. The evolutionary game model of symbiotic decision-making in the entrepreneurial ecosystem is constructed, the evolutionary process of symbiotic decision-making of subjects is analyzed through mathematical derivation, and the symbiotic decision-making process of subjects is simulated through computer simulation to answer how the subjects of the entrepreneurial ecosystem make symbiotic decisions and explore the mechanism of symbiotic formation of the entrepreneurial ecosystem. Then, based on the ecological perspective, the symbiotic evolution model of entrepreneurial ecosystem subjects is constructed from the subject level, the equilibrium point of the evolution of entrepreneurial ecosystem subjects, the stability conditions, and the relationship between the equilibrium point and the symbiosis model are analyzed, and the symbiotic evolution paths of entrepreneurial ecosystem subjects under different symbiosis modes, initial population size, maximum size, and natural growth rate are presented with simulation experiments, respectively. The main characteristics and manifestations of the dynamic evolution of the platform ecosystem are analyzed, and the key competitive factors that determine the dynamic evolution of the platform ecosystem are depicted. Then, according to the inherent characteristic laws of the platform ecosystem, the complex network approach is applied to construct a dynamic evolution model with originality and wide applicability for the change of bilateral user scale. Based on the dynamic evolution process, the relationship between model parameters and business performance is explored, and the trajectory of bilateral user size change over time and the range of parameters are derived by numerical calculation. Finally, using Monte Carlo simulation methods, the dynamic evolution model is used to predict the future operating conditions of platform enterprises, providing a valuation basis for investors to make investment decisions and helping platform managers to formulate business strategies.
\end{abstract}

\section{Introduction}

With the development of the digital economy, traditional enterprises have begun to transform their enterprises into intelligent IOT ecological service platforms, and platforms are playing an increasingly important role in the global market economy and gradually becoming the most important form of economic organization. A platform is a new form of the social division of labor and collaboration organization, with the enterprise as the main body as a link, linking the various users, and its development depends on the increasing maturity of Internet information technology [1]. Although platforms have long existed in the social economy as a medium, they were formed as a form of large- scale collaborative organization only after the Internet became highly popular. Green development in the region cannot be achieved without innovation, and improving green innovation capabilities and driving green development with green innovation is the only option for the region. It has been proved that the innovation ecosystem plays a significant role in innovation management activities, so taking the region as the object, we select innovation organizations to build a regional innovation ecosystem based on green development, which is conducive to promoting green and sustainable development of the region, realizing the multi-benefit creation of economic benefits, research benefits, and ecological benefits, thus enhancing the regional economic strength and innovation capacity, and improving 
the ecological environment. In this paper, we take green development as the guide, integrate the major innovation bodies in the region to build a regional innovation ecosystem based on green development, and study the internal and external relationships of the system and explore its mechanism of action from formation to operation. Then, based on the analysis of the system structure and mechanism of action, 30 regional innovation ecosystems based on green development are constructed in provincial-level regions, and the evaluation model is applied to study the operation efficiency of the system [2]. Realize the multi-benefit creation of economic benefits, scientific research benefits and ecological benefits, thereby enhancing regional economic strength and innovation capabilities, and improving the ecological environment.

The digital economy plays an important role in promoting the innovative development of the economy and society, and ultimately green development. Increasing the proportion of subjects choosing symbiosis at the early stage of entrepreneurial ecosystem establishment, increasing the benefits that subjects obtain through symbiosis, the ex-post transaction costs of subjects exiting symbiosis, and reducing the ex-ante transaction costs of subjects building symbiosis will all promote the formation of symbiosis in entrepreneurial ecosystems [3]. The formation of symbiosis is influenced by six factors: trust, shared vision, relationships, specialization, complementarity, and benefit distribution under three dimensions: cognitive, resource, and economic. Among them, the relationship can promote the achievement of trust and common vision; in the symbiotic evolution of the entrepreneurial ecosystem, at the subject level, the symbiotic evolution path of subjects is influenced by the symbiotic pattern among multiple types of subjects, the stable state scale of symbiotic evolution of each type of subjects is related to its symbiosis coefficient and maximum size, independent of the initial population size and natural growth rate, and the symbiotic evolution speed is related to the natural growth rate of subjects and the initial population [4]. The rate of symbiotic evolution is related to the natural growth rate of the subject and the initial population size and increasing the degree of intersubject dependence in the reciprocal symbiosis model of the entrepreneurial ecosystem is more conducive to the scale of the entrepreneurial ecosystem [5]. At the network level, the entrepreneurial ecosystem symbiotic network has not yet shown the small-world phenomenon; there are some intermediary nodes in the network; the structure of the entrepreneurial ecosystem symbiotic network is between the stochastic network and the scale-free network; the enhancement of the connection scale of the entrepreneurial ecosystem symbiotic network strengthens the degree of intersubject interdependence, and at the same time with the increase of the scale of participating symbiotic subjects and the concentration of the weights of symbiosis formation influencing factors. The degree range of network clustering coefficients, connection size, and degree sub-degrees subsequently increase, and the centrality of the network and the frequency of the degree distribution subsequently decrease.
In terms of resource dependency theory, few entrepreneurs have all the resources needed for opportunity development and must acquire significant external resources to meet their resource needs. The task of resource acquisition is particularly daunting for startups that cannot generate resources and revenues internally and have significant financial constraint issues. Understanding the factors that influence symbiosis formation can help startups to better form symbioses. Therefore, the influencing factors of symbiosis formation in the entrepreneurial ecosystem are a very important question to be answered. In the evolutionary process of establishing, growing, and maturing, the subject of an entrepreneurial ecosystem constantly needs new resources to meet its new development needs, so it needs a constant source of resources from the outside world. The process of subjects continuously acquiring resources from the outside world forms a symbiosis with other subjects. This paper analyzes the case through rooting theory to extract the influencing factors of the symbiotic formation of the entrepreneurial ecosystem and the relationship between the influencing factors, and to explore in depth how each influencing factor affects the symbiotic formation of the entrepreneurial ecosystem. Its theoretical contribution is to systematically refine the influencing factors of entrepreneurial ecosystem symbiosis formation through the method of qualitative research, which enriches the study of entrepreneurial ecosystem symbiosis formation.

\section{Related Work}

Platforms connect groups of users seeking to have their needs met, and the number of users of one type joining a platform affects the utility or benefit of another type of user joining the platform; the greater the number of users gathered in a platform, the greater the value that can be provided to the users and, in turn, the greater the benefit to the platform itself; researchers call this new market form a bilateral market [6]. Bilateral markets are an important part of the modern economic system, a large and growing part of which relies on the functioning of complex markets. Early intermediary markets, exchanges, and traditional media industries, and trade towns are typical representatives of bilateral markets that can provide consumers with the ability to purchase, access, and use multiple products. Bilateral markets play a role in economic society that should not be underestimated, and this paper analyzes the causes and roles of bilateral markets from the basic theory of bilateral markets [7]. The bilateral market theory is closely related to network externalities and multi-product pricing theory, etc. In network externality theory, externalities between end-users cannot be fully internalized, while multi-product pricing theory is dominated by price structure, and multi-product pricing theory argues that price structure is more likely to be distorted by price levels than by market theory [8]. However, network externality theory and multi-product pricing theory gradually reveal their shortcomings in the process of practical application and research [9]. On the one hand, it provides solutions to the problems of insufficient green innovation ability and low efficiency in the current green 
development process in various regions, and on the other hand, it provides a reference for the actual construction of the system and subsequent management. Network externalities usually solve problems such as economies of scale for the same type of users, but in the actual operation process, most of the two sides of a certain network product or a certain platform are different types of users and at the same time multi-product pricing theory, because it does not consider the consumption process of different products. At the same time, multi-product pricing theory also faces various problems in real application because it does not consider the externalities in the consumption process of different products [10].

The value creation of a platform enterprise is based on the participation and interaction of platform users, i.e., for the cross-network externalities between bilateral users, where one side of the platform creates value for other side users, while the platform creates value for bilateral users [11]. In the platform ecosystem, an adaptive pricing strategy is one of the important influencing factors to attract bilateral users to join the platform and use it in the long term, and the platform pricing depends on the marginal cost of the parties involved in the platform, the elasticity of demand coefficient, the strength of the unilateral network effect, the strength of the cross-network effect, and the strategic behavior of the platform [12]. The cross-network effect determines the price structure, and the platform charges a higher price to the users who benefit more. The greater the level of differentiation in the demand for the platform on one side of the market, the higher the pricing of the platform to the other side of the market in the optimal price structure [13]. However, the above literature also has limitations in that it takes the network effect as a perspective to enhance the bargaining power of the platform, capturing as much as possible the total value created within the system and thus enhancing its market competitiveness, without considering the redistribution of value in the platform ecosystem and the conversion rate of potential users and the sustained usage of existing users.

Ecosystems are complex in structure, consisting of biotic components responsible for production, consumption, and decomposition and abiotic components that provide the various resources needed for biological growth, with the system level divided from low to high into individuals, populations, communities, and ecosystems, from high to low containing one layer. The abiotic components are the ecological environment, also known as ecological factors, which act directly or indirectly on the living organisms within the ecosystem and play a vital role in system. A system generally possesses numerous environmental factors that inhibit or promote the survival and development of various living organisms within the system. The various environmental factors are interrelated and a change in one may cause a change in another. Each ecological factor is a unique individual, performing its function within the ecosystem, and is irreplaceable. An ecosystem is an open-cycle system with open boundaries. Living organisms within the system are interconnected and maintain interactions with the outside world. Biomes and the environment adapt and change to each other as they operate, evolving to achieve the best possible state of the system.

\section{Characterization and Evolutionary Analysis of the Digital Economy Ecosystem for the Interspecies Competition Model}

3.1. Interspecies Competition Model for Digital Economy Ecosystem Design. Driven by the high speed of innovation in the digital economy, dynamic competition due to the continuous pursuit of innovation by traditional enterprises has become one of the characteristics of competition in the platform market. An important feature that distinguishes platform enterprises from traditional enterprises is the decolonization of the platform, forming a vertical industry chain or ecosystem. The positive and negative feedback effects brought about by high-frequency innovation and network effects make the rise or collapse of platform enterprises more rapid, causing different degrees of impact on the industry chain and ecosystem, which therefore causes both rapid changes in the competitive landscape of the platform market and huge competitive pressure on the incumbent platform enterprises [14]. In the platform ecosystem, as the intensity of network effects increases and the number of users continues to expand, the relationships between users on each side are complicated and diversified, and internal competition in the platform ecosystem stimulates and even intensifies. Currently, under the vigorous development of the digital economy and Internet technology, many industries have started to rely on the Internet, and traditional enterprises have transformed and upgraded to adopt bilateral platforms to carry out various business activities of enterprises. Bilateral platforms have long been widely present in traditional products and emerging industries, such as department stores, dating sites, search engines, credit card systems, software industries, etc. Obtain the dynamic evolution model equation of the platform ecosystem under the network perspective. The proposal of this model is scientific and original, and it is quite different from the analysis model used in the existing research results. The quantitative model constructed in this article is more practical and superior. Bilateral platforms have always played an extremely important role, linking buyers and sellers, complementary traders, suppliers, and other bilateral (multi)-sided user groups. The internal growth logic and market competition of bilateral (multi)-sided platform enterprises are somewhat different from those of traditional enterprises, and exploring the dynamic evolution of bilateral platforms is a discussion of the market share of platform enterprises in the market competition. The platform enterprise itself can constitute a marketplace, and the community of buyers and sellers, together with complementary service providers and competing platforms, forms the ecosystem within the platform. Similarly, the dynamic evolution of a platform ecosystem is the competitive development of the platform, and managers need to focus on both the profit growth from interactions and the key 
competitive factors that affect their market share during their operations.

The platform ecosystem contains individuals, both supply-side users and demand-side users, as well as potential users in the wait-and-see stage, and there are network relationships between different users and individuals, and one small network constitutes the whole platform ecosystem as a complex network, so the platform ecosystem has a multidimensional spatial structure. Based on this, considering that it is difficult to analyze everyone in the system, this paper draws on existing research and uses mathematical methods to downscale the multidimensional model and analyzes the user interactions at the meso level through the micro-individuals and macro-whole and discusses the average market share of the platform ecosystem through the relative value of user size to measure the evolution and competition of the platform ecosystem. Based on the complex dynamics approach, it is known that, in a highdimensional interaction network, the dynamical system of the dimensionality reduction treatment contains two coupled ordinary differential equations: one on the supply side and one on the demand side. Analyze the growth, evolution, and competition process of a platform from the start-up stage layer by layer. As a single innovation unit, the innovation organization is the basic component of the newly constructed system.

$$
\begin{gathered}
a_{i}^{s} S_{i}=\frac{\alpha^{3}}{1+\alpha} S_{\mathrm{eff}}^{2}, \\
\beta_{i i}^{S} \ll \beta_{i j}^{S} .
\end{gathered}
$$

For further simplification, we can ignore the effect of competition between bilateral users with the effect of trends and word-of-mouth effects and therefore can write

$$
\begin{aligned}
& \sum_{j=1}^{N s} \beta_{i i}^{S} S_{i} S_{j} \simeq \beta D_{\text {eff }}, \\
& \sum_{i=1}^{N D} \beta_{i i}^{S} D_{i} S_{j} \simeq \frac{\lambda^{2}}{1+\lambda} \beta D_{\text {eff }} .
\end{aligned}
$$

Cross-network effect strength is the sum of the strength of multiple interactions calculated from the strength of a single individual in the system; however, this paper is to explore the dynamic evolution of the platform ecosystem in a competitive marketplace and needs to portray its overall impact on the size of bilateral users by calculating the relative value of the average interaction strength, i.e., the cross-network effect strength, across the system [15]. By examining the literature and incorporating the market characteristics of platform firms, this paper uses the unweighted average method to calculate the intensity of the cross-network effect for bilateral users. Schematic diagram of principle of interspecific competition model as shown in Figure 1.

$$
\gamma_{s}=\frac{\sum_{i=1}^{N_{D}} \beta_{i i}^{S} D_{i} S_{j}}{\beta D_{\mathrm{eff}}} .
$$

A major difference between the dynamic evolution model of the platform ecosystem constructed in this paper and those in previous studies lies in the treatment approach adopted in this model. The object of this paper is the entire platform ecosystem, which contains buyers and sellers or service providers and users as well as complimentary service providers, and the relationships between the various players and the competitive market environment together constitute a complex internal platform ecology. This paper takes this complex ecosystem as the object of study and analyzes the growth evolution and competition process of a platform from the start-up stage layer by layer by dissecting the parameters that influence the interaction of the members in the system. Innovative organizations, as individual innovation units, are the basic components of the newly constructed system [16]. The regional innovation ecosystem based on green development contains a total of six innovation organizations: local governments, green development enterprises, the public, universities and research institutions, social service institutions, and financial institutions, which correspond to the six functional subjects of system innovation, efficiency innovation, service innovation, technology innovation, financial innovation, and demand innovation of the system, and communicate with each other and transform energy through the fluids generated by each of them in the system. They can fully exert their respective effects and collaborate to serve the system.

$$
\begin{aligned}
\max p & =\lim _{m \rightarrow \infty} \frac{\left|m-\sum_{i=1}^{m} S_{i}^{-} / x_{i k}\right|}{m+\sum_{i=1}^{m} S_{i}^{+} / x_{i k}}, \\
\mathrm{TC} & =\left[\frac{D^{t}\left(x_{t}, y_{t}\right)}{D^{t+1}\left(x_{t+1}, y_{t+1}\right)} \times \frac{D^{t}\left(x_{t}, y_{t}\right)}{D^{t+1}\left(x_{t+1}, y_{t+1}\right)}\right]^{2}, \\
\mathrm{EC} & =\frac{D^{t+1}\left(x_{t+1}, y_{t+1}\right)^{2}}{D^{t}\left(x_{t}, y_{t}\right)^{2}} .
\end{aligned}
$$

Enterprises are the operators of regional production operations and the creators of economic profits, and it is natural that the region cannot go green without green development enterprises, which insist on applying green innovation technologies to create economic profits for the region without sacrificing the environment, and are the benefit innovation subjects of the regional innovation ecosystem based on green development. Green development enterprises aim to create economic and ecological benefits and aim to create ecological and economic benefits that integrate the two benefits for the region. Green development enterprises generally flow through the system in the form of benefit streams, creating their economic benefits while providing financial support for other innovation subjects, 


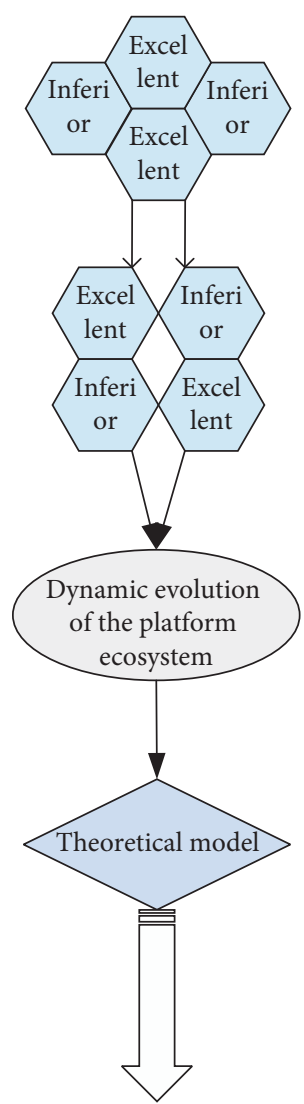

Excellent

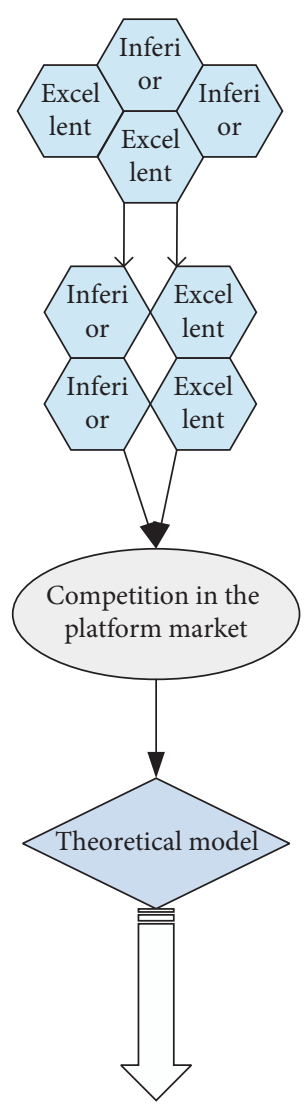

Excellent

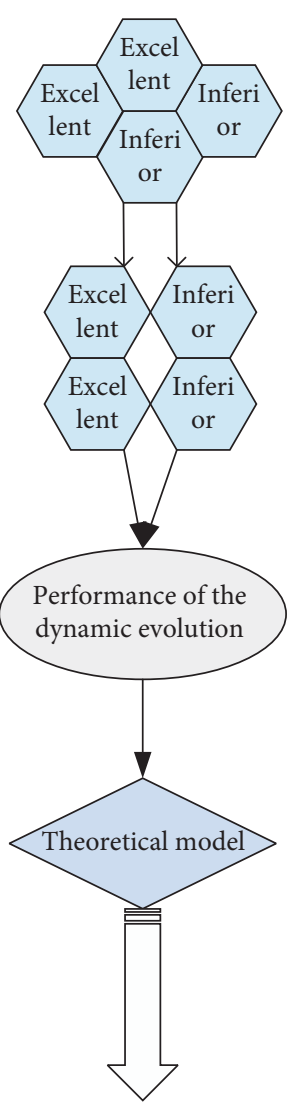

Excellent

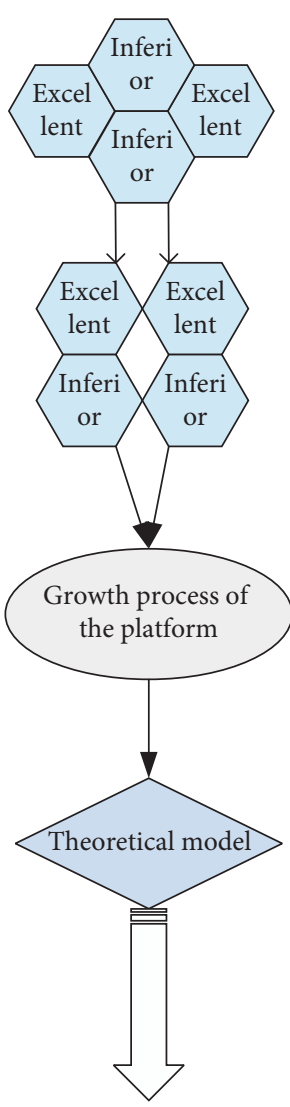

Excellent

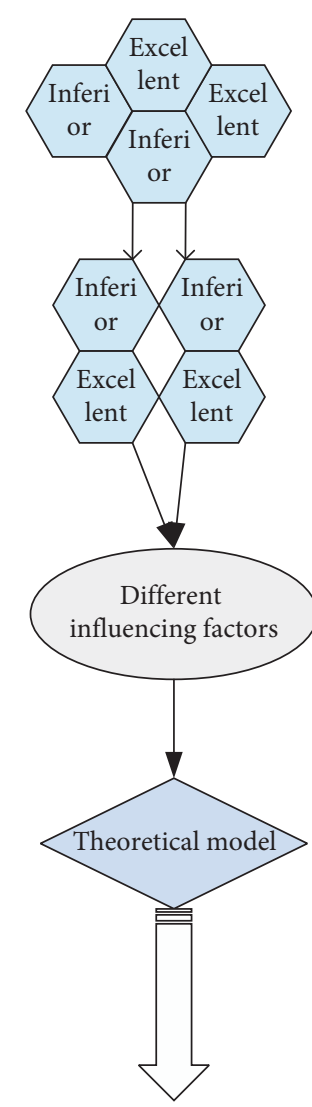

Excellent

FIgURE 1: Principle of interspecific competition model.

such as investing funds to support the research and development of green innovation technologies in universities and research institutions, sponsoring the activities of green environmental protection organizations and other industry associations, contributing to the improvement of the ecological environment and creating certain ecological benefits. After gaining an in-depth understanding of the regional market demand and competition mechanism, green development enterprises actively seek green product innovation through self-development or enterprise cooperation to create green best-selling products that meet market demand and create ecological economic benefits, as shown in Figure 2.

Next, we discuss the proposition from three aspects: the main body of the entrepreneurial ecosystem, the operation of the system, and the governance of the system. In terms of the main body of the entrepreneurial ecosystem, the main body of the entrepreneurial ecosystem must actively construct symbiosis and form a close economic community. It is argued that increasing the benefits that subjects in an entrepreneurial ecosystem obtain through symbiosis, the expost transaction costs of exiting symbiosis, and reducing the ex-ante transaction costs of constructing symbiosis for subjects in an entrepreneurial ecosystem can facilitate the formation of symbiosis for subjects in an entrepreneurial ecosystem. The benefits gained by subjects in the entrepreneurial ecosystem through symbiosis, the ex-ante transaction costs of constructing symbiosis, and the ex-post transaction costs of exiting symbiosis affect their symbiosis decisions [17]. We next discuss the proposition in terms of the subjects of the entrepreneurial ecosystem, the operation of the system, and the governance of the system. In terms of the subjects of the entrepreneurial ecosystem, the subjects of the entrepreneurial ecosystem should actively build a symbiosis to form a close economic community and bind their interests together; the closer the relationship between the subjects, the greater the value created together, and the more benefits the entrepreneurial enterprise and related subjects obtain through the symbiosis.

$$
\begin{aligned}
\frac{\mathrm{d} U}{\mathrm{~d} t} & =U\left(a+b U^{2}\right), \\
\lambda_{1}(h) & =\operatorname{Inf}\left\{\int_{\Omega} \frac{[\nabla \varphi(x)]^{2}}{\int_{\Omega} h(x) \varphi(x) \mathrm{d} x}\right\} .
\end{aligned}
$$

First, existing studies still focus on the impact of traditional industrial structure changes on green development, failing to unify the role of the digital economy on green development in a research framework, and although a large number of research results demonstrate the possibility of the digital economy influencing regional green development in multiple ways, the mechanism of the role of the digital economy in driving the greening transformation of the 


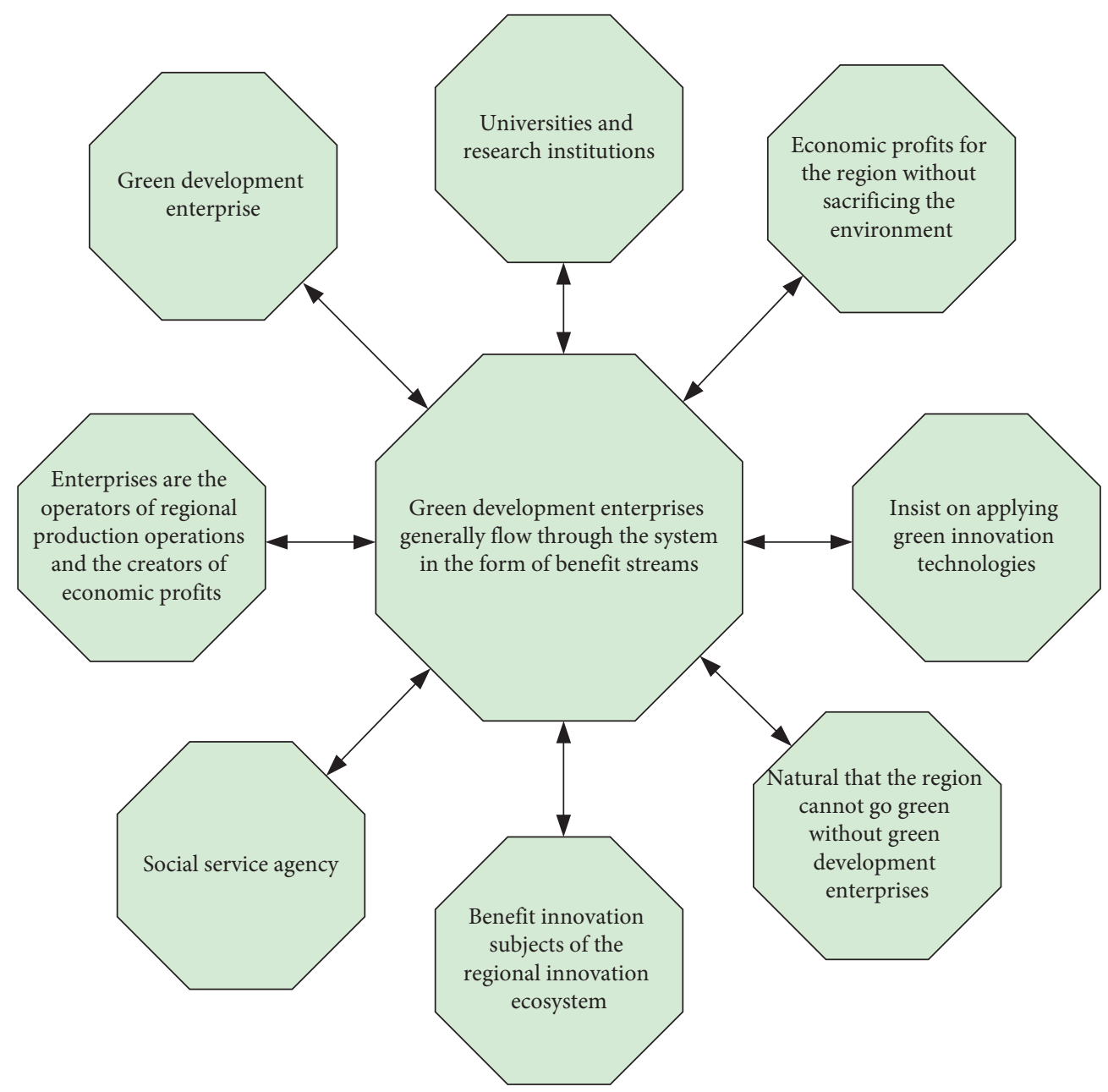

Figure 2: Digital economy ecosystem functions.

regional economy still lacks systematic analysis; second, existing studies ignore the endogeneity of the level of digital economy and economic development, as digital economy is a product of the stage of socioeconomic development and progress, so there may be a causal link between the level of development of digital economy in a region and the level of economic development in the region, and its endogeneity must be controlled to ensure the credibility of the results; third, the existing studies mostly focus on the general impact of digital economy on regional development, but ignore the differential impact of the digital economy on regions at different stages of development, and whether the digital economy dividend can narrow the development gap between regions remains to be verified.

\subsection{Ecosystem Characterization and Evolutionary Design.} Regional green total factor productivity is measured from an efficiency perspective using data envelopment analysis or stochastic frontier analysis. The main principle of this model is to measure the undirected undesired output, i.e., under a certain input, the larger the desired output and the smaller the undesired output, the higher the economic efficiency of the region, to measure whether the region can achieve high desired output with lower input indicators and undesired output, as shown in Figure 3.

Spatial weight matrix can reflect the dependency relationship between spatial decision units and assign them as weights in the regression equation to influence the size of correlation; therefore, the reasonable construction of spatial weight matrix has a crucial role in the validity of the empirical test results [18]. The commonly used spatial weight matrices are adjacency distance matrix, distance criterion matrix, and economic linkage matrix, etc. Among them, the adjacency distance matrix can be divided into Queen adjacency (two decision units have common boundary or common node between them), Rook adjacency (two decision units have common boundary between them), and K-order adjacency matrix (two decision units are high adjacency) according to the different adjacency relationship between them. The standard matrix can be divided into finite distance matrix, general distance matrix, and distance ranking matrix according to the distance criteria it uses; the smaller the distance between decision units, the smaller their degree of association; the commonly used distances are latitude and longitude distance, spherical distance, etc.; economic linkage matrix is the most common spatial weight matrix in the last two years; the theory that certain economic 


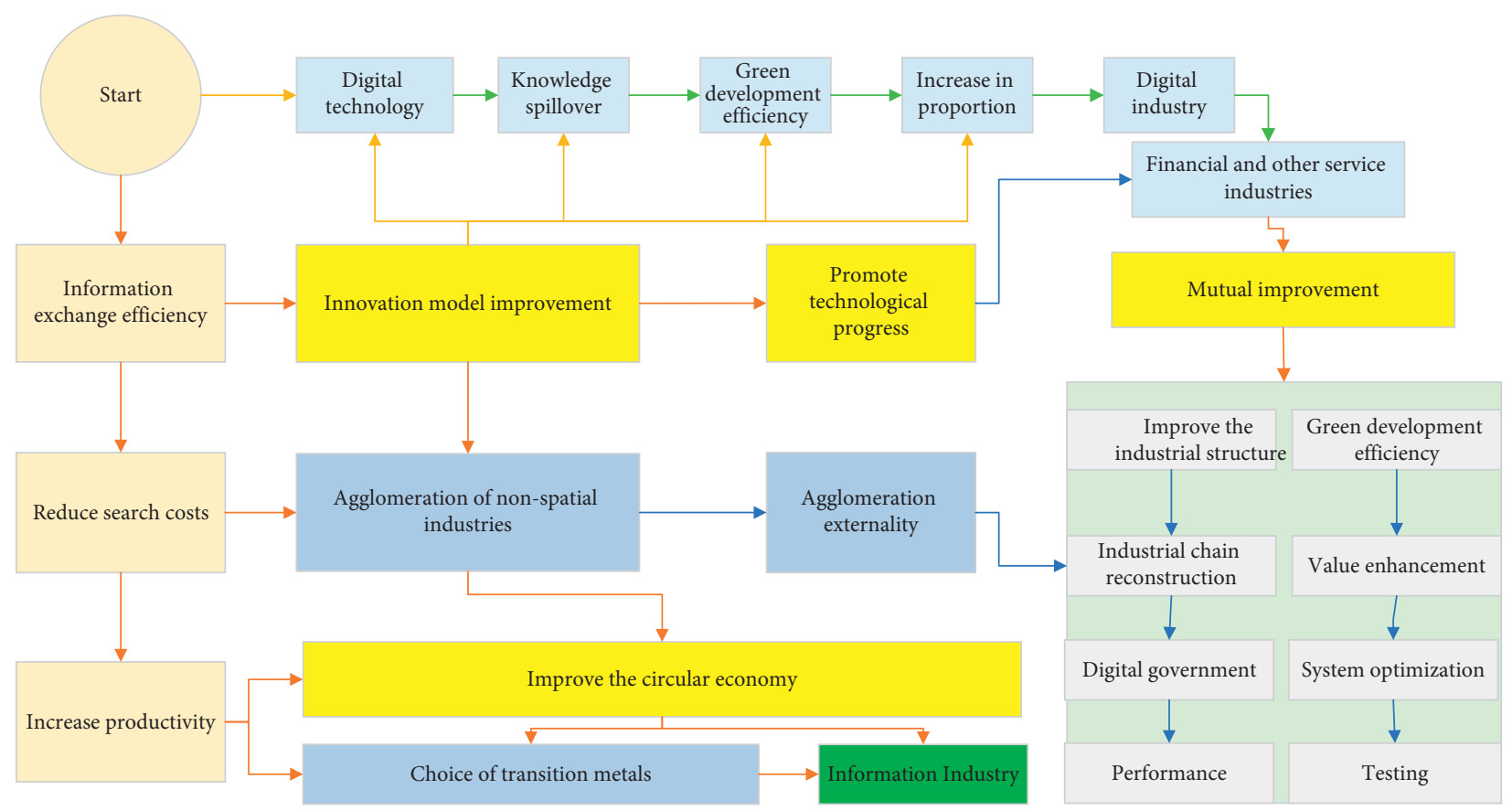

FIgURE 3: Mechanisms of the impact of the digital economy on regional green development.

characteristics between two decision units are similar will also shorten their spatial distance. Some spatial weight matrices are constructed based on the scale of economic development, the scale of society, or the scale of human capital to characterize the correlation of certain aspects of economic characteristics between decision units.

$$
\begin{aligned}
& W_{i j}=W_{d} \operatorname{diag}\left(\frac{K_{1}}{K}, \frac{K_{2}}{K}, \ldots, \frac{K_{m}}{K}\right), \\
& W_{i j}=W_{d} \operatorname{diag}\left(\frac{E_{1}}{E}, \frac{E_{2}}{E}, \ldots, \frac{E_{m}}{E}\right) .
\end{aligned}
$$

Theoretical saturation refers to the inability of a new sample of studies to define new categories and concepts or to generate new insights. This paper found that the categories and concepts were largely saturated when coding the fifth sample profile, and when coding the sixth sample profile, no new categories or concepts emerged, and the analysis of this paper's rooted theory had reached saturation. In the entrepreneurial ecosystem, subjects should fully consider the impact of trust, shared vision, relationships, specialization, complementarity, and benefit distribution on the formation of symbiotic relationships and actively enhance the subjects' capabilities to build the subjects' symbiotic relationship network more effectively, to better access valuable resources. The subjects of the entrepreneurial ecosystem can cultivate their entrepreneurial credibility and corporate reputation through strong and weak relationship networks and form trust between subjects through active communication to reach a common ideal and a common vision under a consistent philosophy. Based on trust and common vision, further, consider the complementarity of symbiotic subjects from three aspects: resource complementarity, talent complementarity, and technology complementarity, and measure the specialization of symbiotic objects from two aspects: technology specialization and knowledge specialization, and reach appropriate and consistent rules of benefit distribution through reasonable equity distribution, option incentive, and partnership system, to form a complex symbiotic relationship step by step from a single symbiotic relationship network [19]. As the symbiotic relationship of the entrepreneurial ecosystem increases and tightens, the degree of dependence between subjects gradually increases, and each subject is indispensable in the symbiotic relationship, and in the process of coevolution, the scale and vitality of the entrepreneurial ecosystem are gradually enhanced, as shown in Figure 4.

The heterogeneous impact of the digital economy on regions can be broadly summarized into two points: first, there is a link between the level of economic development and the level of information technology; when the region has a higher level of economic development, its social system is more complete, the channels of knowledge dissemination are more diversified, the acceptance of new things is more accommodating, and it is more conducive to the development and dissemination of information technology; therefore, regions with a higher level of economic development can often provide a more favorable environment for the development of digital. Secondly, there is a difference in the speed of the diffusion and spread of new technologies between different regions, which is mainly caused by the gap in the level of knowledge development and the foundation of the region's development environment. For these reasons, the development of the digital economy may make the task of catching up more difficult for regions that are lagging in economic development, as they not only have to continue to popularize the previous generation of information technology, but also must grasp the development dividend 

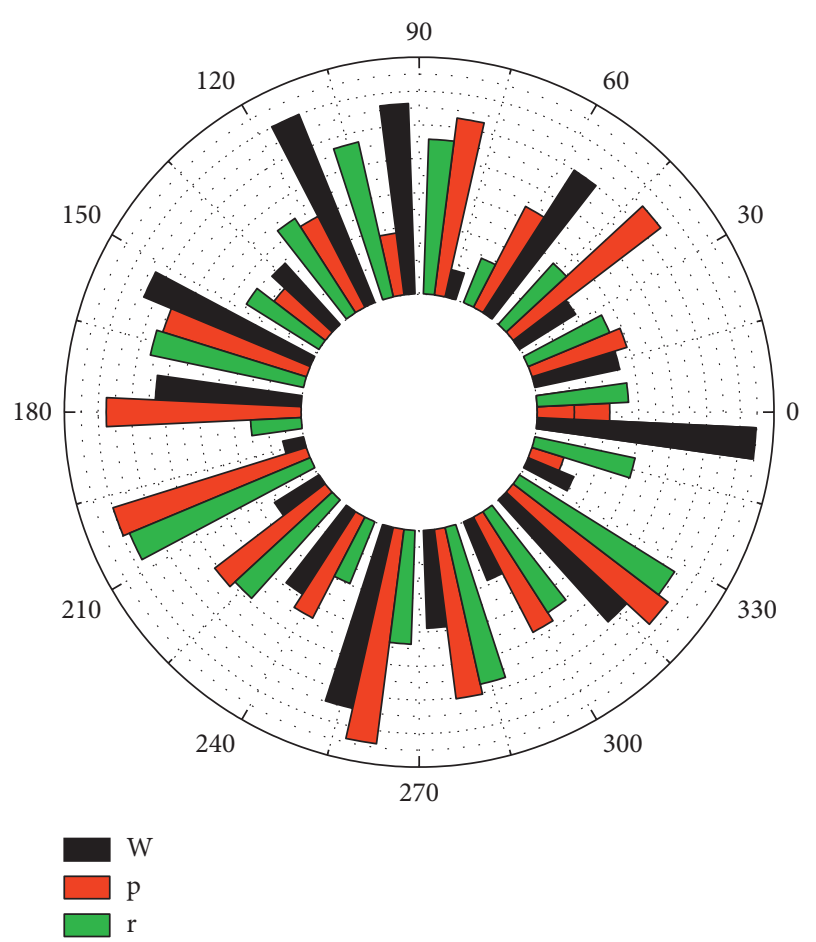

FIGURE 4: Effect of environmental stress on parameters, i.e., angle, distance, and number of branches.

brought by the new generation of information technology as soon as possible, and in the process, there is a high risk of creating a widening new development gap [20]. BIM consulting units are emerging groups created after BIM intervention projects. The base number is small, but they have good development prospects. In addition, because design units undertake core design functions, they have certain advantages in terms of talents, technology, and capital.

The impact of the digital economy on the level of regional green development is mainly realized through two major paths: promoting the efficiency of information transmission and the economic benefits brought by the digital industry itself, so this paper measures the possible impact of the digital economy on the information transmission in its region by the level of penetration of the digital economy development, i.e. the breadth of the digital economy, and the quality of the digital economy development, i.e., the depth of the digital economy development, to measure the digital industry itself in the region value creation capability.

\section{Analysis of Results}

4.1. Digital Economy Ecosystem Performance. In the BIM ecosystem, there is often no competitive relationship between populations with different ecological niches. The possible reason for the competitive relationship is that the original populations upgrade their enterprises in the context of technological innovation and information development, and the core populations integrate upstream and downstream enterprises in the industry chain, thus generating overlapping ecological niches with upstream and downstream populations in the industry chain and inducing competitive relationships, such as design units and BIM consulting units, and more and more design units set up independent BIM departments for completing BIM-related work. Therefore, with design institutes as the population and BIM consulting units as the population, the initial population size, natural growth, and competitive advantage relationship between the two are initially set by predicting the model parameter size relationship. First, denoting the resource constraint, which in this context can be expressed as the maximum value of the BIM market size, the initial environmental capacity of both is assumed to be the same. In addition, because the design unit itself is the core population in traditional engineering projects, its initial population is large; in comparison, BIM consulting unit is an emerging population generated after BIM intervention in engineering; the base quantity is smaller, but has better development prospects. In addition, because the design unit undertakes the core function of design and has certain advantages in talent, technology, and capital, it is more competitive in the process of competition advantage, as shown in Figure 5. As shown in Figure 5, the simulation result corresponds to case 2 of the competition model, the species will dominate, and the species peal will gradually die out, as the design unit is not yet able to complete the industrial upgrading in the short term and integrate the function of the BIM consulting unit.

BIM application is mainly outsourced BIM consulting unit, so the number of BIM consulting units rises faster in the short term. However, as the design unit continues its core position in project engineering and integrates the functions of BIM consulting units in the later stage of development, the number of BIM consulting unit population decreases, while the design unit population gradually converges to the maximum environmental capacity and eventually maintains a stable state. Comparing the environmental capacity $\mathrm{K}$ values, it can be found that the competitive relationship between the two mutually suppresses each other's population growth situation and stabilizes below the environmental capacity.

The complex factors affecting the evolution of the BIM ecosystem include both qualitative and quantitative variables, increasing the complexity of the model and the difficulty of modeling. For qualitative variables, it is necessary to choose suitable quantitative means to quantify the variable under the premise of being in line with reality. As for quantitative variables, it is necessary to refer to relevant statistical yearbooks or research reports, and for some unavailable data, it is necessary to use mathematical regression or empirical methods to predict them. If historical data on temporal changes are available for a pair of causal elements at the same time, the table function between the two can be obtained by arranging them in time. Since realistic data are very limited, data prediction will produce a priori errors in the evolutionary simulation of the BIM ecosystem. In this paper, to minimize the impact of errors, sufficient data research conducted and only its short-term development over the period 2011-2030 were explored, focusing on qualitatively illustrating the evolutionary passage of the BIM ecosystem, as shown in Figure 6. 


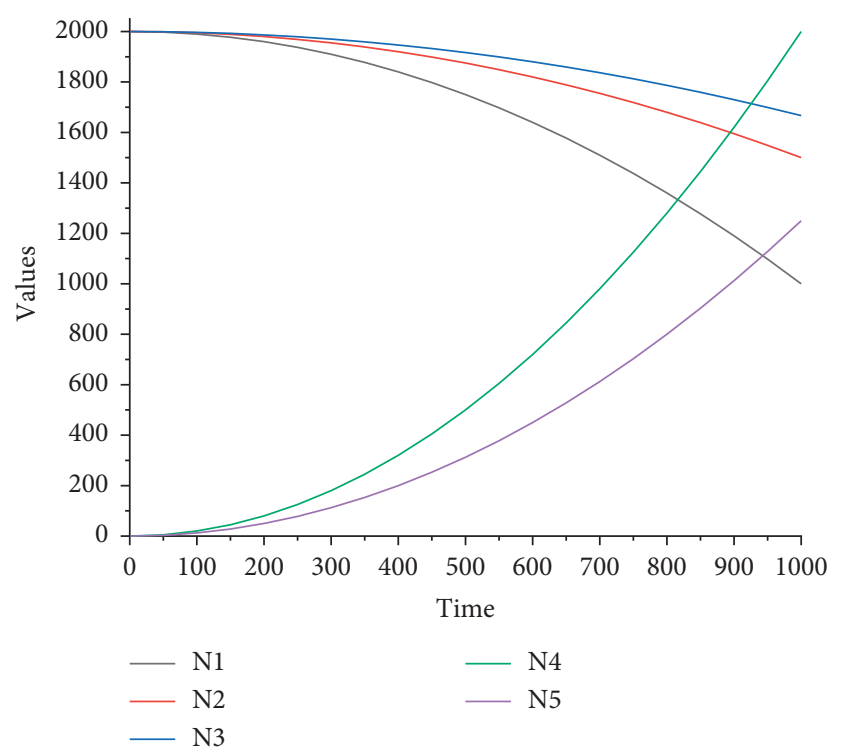

Figure 5: Interspecific competition model imitating its results.

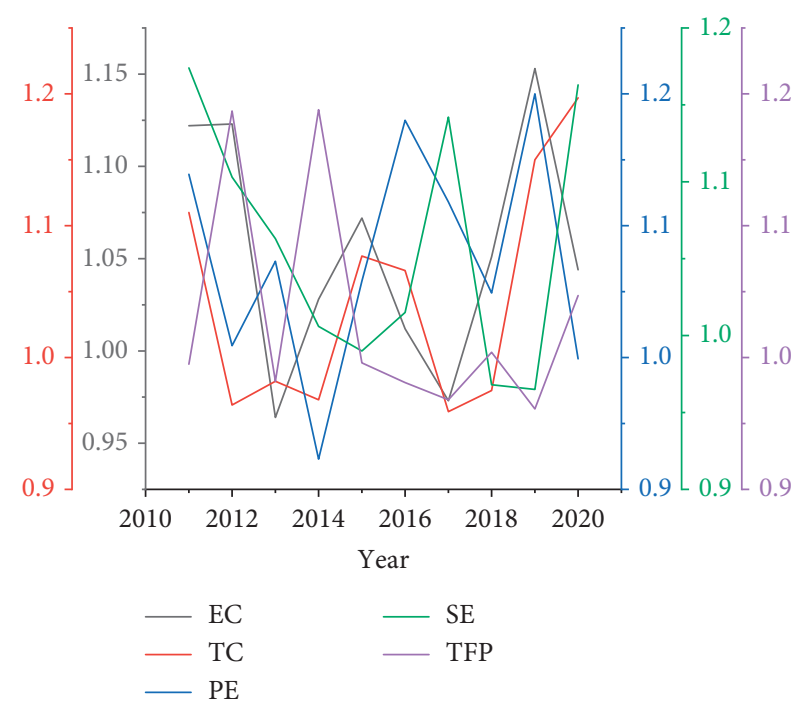

FIgURE 6: Average index of innovation ecosystems by year and its decomposition results.

The operational efficiency of the system is affected by many factors, and the existing relevant studies mainly select corresponding indicators from local government intervention, the degree of openness to the outside world, the educational environment, the repayment capacity of enterprises, and the level of economic development for the analysis of the influencing factors. In this paper, when selecting the influencing factors, we draw on the existing studies on the one hand and select the corresponding influencing factors from the perspective of the six innovation environments that affect the system on the other hand. Based on the six types of innovation ecological environment, policy, economy, science and technology, resources, market, and culture, this paper chooses to study the influencing factors of the operational efficiency of the regional innovation ecosystem based on green development from six aspects, environmental regulation, economic openness, technology market, energy consumption, industrial structure and culture, and education, and explores the methods to improve the operational efficiency of the system.

The total amount of investment in environmental pollution control does not pass the significance test and does not meet the original hypothesis, and there is no significant relationship with the system operating efficiency, and the change of the total amount of investment will not directly cause the change of the system operating efficiency. The reason is that the domestic environmental regulation emphasizes the form rather than the initiative, the surface rather than the supervision, and some local governments do not pay attention to the implementation of pollution reduction policies, and the enterprises' emission theft and emission increase are repeatedly prohibited, and the investment in environmental pollution control does not effectively improve the ecological environment, which makes the environmental regulation fail to play a role in improving the operational efficiency of the system. The total foreign investment in each region and the operating efficiency of the system shows a significant positive correlation, and the operating efficiency of the system increases with the increase of the total foreign investment in each region, which is consistent with the original hypothesis. On the one hand, the arrival of foreign investors brings advanced technology, which reasonably use and innovate to improve the development of domestic green innovation technology; on the other hand, it intensifies the competition among enterprises, which will eliminate the winners and the losers, leaving behind green development enterprises and promoting the transformation of market structure, thus improving the efficiency of the system.

\subsection{Results of the Evolution of Ecosystem Characteristics.} Through the math lab software, the symbiotic evolution process of startups and investment institutions, startups and large enterprises, startups and intermediaries, and startups and universities and research institutes are found to be consistent when the relevant subjects are set as investment institutions, large enterprises, intermediaries, or universities and research institutes with the same parameters, and the symbiotic evolution path of startups and investment institutions is taken as an example in this paper to simulate the symbiotic evolution path of startups. The relevant subjects represent investment institutions in the simulation results below. First, we explore the symbiotic evolution between startups and related subjects under different symbiosis models. We assume that the natural growth rate, maximum size, and initial size of the subjects under different symbiosis coefficients are constant. Specifically, this model is used to analyze the overall evolutionary trend, such as the dynamic evolution of a platform or the overall evolutionary development of an industry composed of multiple platforms, focusing on the wholeness and unity of the enterprise ecology or industrial ecology, which is convenient for the relevant personnel to conduct research and analysis or 
formulate management strategies. In addition, the superiority of this model is also reflected in the mathematical analysis. When using the model for research and analysis, a computer can be used for simulation and analysis to discuss the probability distribution of the influencing factors or dynamic parameters under study one by one and further get the range of action of the parameters. In contrast, the general macroscopic model cannot be simulated, and it is not possible to discuss the probability distribution of the influencing factors or dynamic parameters under study, and thus the results cannot be analyzed in depth. Therefore, the dynamic evolution model of the platform ecosystem constructed in this paper combined with the complex network approach is innovative compared with the traditional research methods and existing models and has certain universality and superiority, as shown in Figure 7.

Some spatial weight matrices are constructed according to the scale of economic development, social scale, or human capital to characterize the correlation of certain aspects of economic characteristics between decision-making units. It can be concluded that the interaction between bilateral users will directly affect the operational performance of the platform, first in terms of the number of users. Due to the cross-network effect, users on one side increase, and users on the other side increase and vice versa. In the above analysis, the positive and negative effects are given to the platform operation, both have the same effect on the change of user size, and the bilateral user size always keeps changing in the same direction; at the same time, there is a critical value for the effect of cross-network effect on the system evolution, and when the critical moment is reached, there will be a bifurcation of the effect and the effect has a certain periodicity. According to the relationship between the trend and word-of-mouth effects and the business performance parameters of platform enterprises, the trend and word-ofmouth effects in the platform ecosystem will directly affect the adoption decisions of demand-side users, especially for potential users who are easily influenced by the trend and word-of-mouth factors due to the existence of a certain herd mentality among consumers. When trends and word-ofmouth play a positive role, consumer-side users tend to adopt the platform based on positive feedback from other users and thus also attract more suppliers based on their feedback suggestions. When trends and word-of-mouth effects play a negative and negative role on the platform, users on the consumer side choose other platforms, as shown in Figure 8.

Distance criteria matrix can be divided into a finite distance matrix, general distance matrix, and distance ranking matrix according to the distance criteria used; the smaller the distance between decision units, the smaller the degree of correlation; the commonly used distances are latitude and longitude distance, spherical distance, etc.; economic linkage matrix is the most common spatial weight matrix in the past two years; the theory that some economic characteristics between two decision units are similar will also shorten their spatial distance. Therefore, some spatial weight matrices are constructed according to the scale of economic development, the scale of society, or the scale of

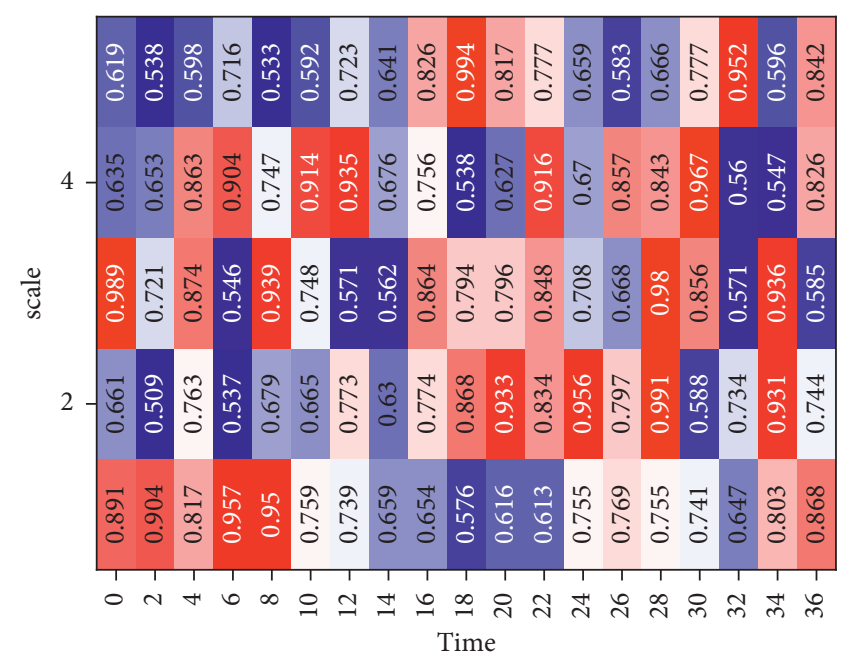

FIgURE 7: Impact of scale.

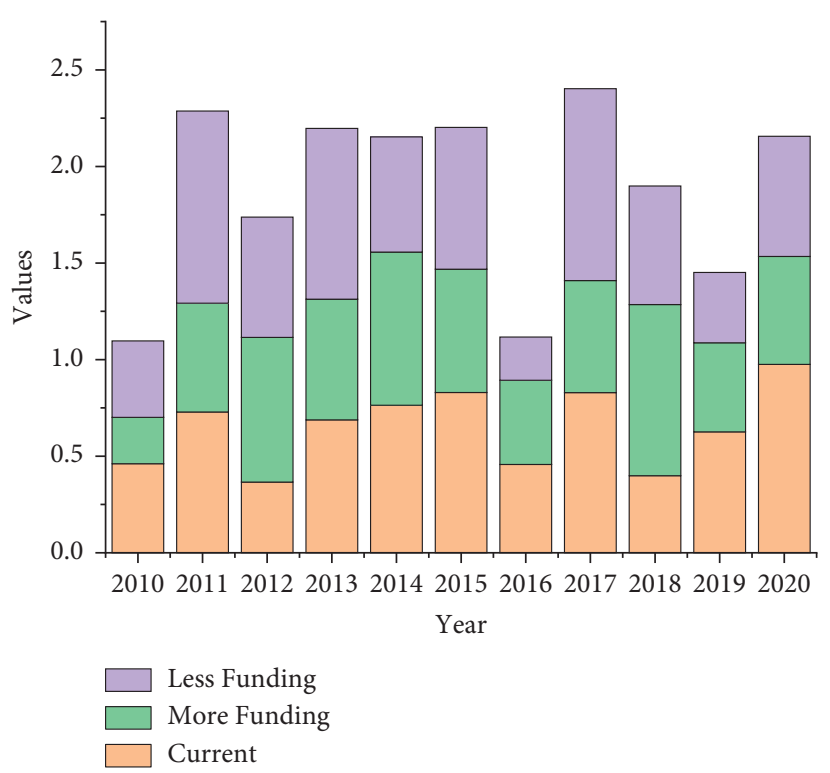

Figure 8: Evolution under different scenarios.

human capital to characterize the relevance of certain aspects of economic characteristics between decision units. The degree of the region's openness to the outside world, i.e., the amount of its foreign direct investment, has a significant contribution to the level of green development in the region, and the empirical results confirm that foreign direct investment may have a direct or indirect positive effect on the transformation and upgrading of the region's economic structure through the introduction of foreign production technology, management model improvement, and knowledge spillover.

\section{Conclusion}

The development of the digital economy has a significant contribution to the improvement of the level of regional green development, and this conclusion still holds after the 
introduction of instrumental variables for robustness testing. The impact of the digital economy on the regional green development level has a significant spatial spillover effect, and the increased level of development of the digital economy in a region not only promotes local green development but also positively affects the green development level of related linked areas. The scale-dependent self-organization process also plays a key role in the formation of irregular vegetation spatial patterns in salt marsh wetlands; the analysis of plant root network structure reveals that self-organization can not only improve primary productivity, but also influence vegetation physiological behavior characteristics, such as changing the distribution of aboveground and below-ground biomass, affecting root branching direction, length, and number, and thus improving plants' adaptive capacity to environmental stresses. The dynamic evolution model of the platform ecosystem can be used to predict the future growth evolution trajectory and operation of platform enterprises. Platform operators can use the generic model proposed in this paper to conduct simulations to predict the future operation and development of the platform and follow this method to plan the development strategy of the enterprise, identify problems, and take effective measures in time to avoid a continuous decline in the platform's business performance. In the sharing economy platform, managers can predict the future development trend of this emerging and popular industry and target their competitiveness to gain a larger market share when competing with competitors. In addition, venture investors can make cooperative valuation of the platform based on the model's simulation results on the future business performance of the platform companies and then make investment decisions to avoid losses to their interests.

\section{Data Availability}

The data used to support the findings of this study are available from the corresponding author upon request.

\section{Conflicts of Interest}

The authors declare that they have no conflicts of interest.

\section{Acknowledgments}

This research was supported by Hebei Social Science Fund Project: Research on Measuring the Poverty Alleviation Effect and Promotion Path of e-Commerce in Hebei Province (No. HB20GL018) and Hebei Social Science Development Research Project: Research on Measuring the Poverty Alleviation Effect of e-Commerce in Hebei Province (No. 20200203119).

\section{References}

[1] L. Govaert, E. A. Fronhofer, S. Lion et al., "Eco-evolutionary feedbacks-theoretical models and perspectives," Functional Ecology, vol. 33, no. 1, pp. 13-30, 2019.
[2] S. P. Hart, M. M. Turcotte, and J. M. Levine, "Effects of rapid evolution on species coexistence," Proceedings of the National Academy of Sciences, vol. 116, no. 6, pp. 2112-2117, 2019.

[3] S. Mammola, M. A. Arnedo, C. Fišer, P. Cardoso, A. J. Dejanaz, and M. Isaia, "Environmental filtering and convergent evolution determine the ecological specialization of subterranean spiders," Functional Ecology, vol. 34, no. 5, pp. 1064-1077, 2020.

[4] M. C. Urban, S. Y. Strauss, F. Pelletier et al., "Evolutionary origins for ecological patterns in space," Proceedings of the National Academy of Sciences, vol. 117, no. 30, pp. 1748217490, 2020.

[5] A. C. Westerband, J. L. Funk, and K. E. Barton, "Intraspecific trait variation in plants: a renewed focus on its role in ecological processes," Annals of Botany, vol. 127, no. 4, pp. 397-410, 2021.

[6] B. M. Taylor, J. H. Choat, E. E. DeMartini et al., "Demographic plasticity facilitates ecological and economic resilience in a commercially important reef fish," Journal of Animal Ecology, vol. 88, no. 12, pp. 1888-1900, 2019.

[7] I. Martínez Cano, H. C. Muller-Landau, S. J. Wright, S. A. Bohlman, and S. W. Pacala, "Tropical tree height and crown allometries for the Barro Colorado Nature Monument, Panama: a comparison of alternative hierarchical models incorporating interspecific variation in relation to life history traits," Biogeosciences, vol. 16, no. 4, pp. 847-862, 2019.

[8] M. Pontarp, A. Brännström, and O. L. Petchey, "Inferring community assembly processes from macroscopic patterns using dynamic eco-evolutionary models and Approximate Bayesian Computation (ABC)," Methods in Ecology and Evolution, vol. 10, no. 4, pp. 450-460, 2019.

[9] S. Mazguene, M. Rossi, M. Gogliettino et al., "Isolation and characterization from solar salterns of North Algeria of a haloarchaeon producing a new halocin," Extremophiles, vol. 22, no. 2, pp. 259-270, 2018.

[10] P. Yu, J. Mathieu, Y. Yang, and P. J. J. Alvarez, "Suppression of enteric bacteria by bacteriophages: importance of phage polyvalence in the presence of soil bacteria," Environmental Science \& Technology, vol. 51, no. 9, pp. 5270-5278, 2017.

[11] S. Valverde, B. Vidiella, R. Montañez, A. Fraile, S. Sacristán, and F. García-Arenal, "Coexistence of nestedness and modularity in host-pathogen infection networks," Nature Ecology \& Evolution, vol. 4, no. 4, pp. 568-577, 2020.

[12] E. Tromeur and L. Doyen, "Optimal harvesting policies threaten biodiversity in mixed fisheries," Environmental Modeling \& Assessment, vol. 24, no. 4, pp. 387-403, 2019.

[13] A. Sakavara, G. Tsirtsis, D. L. Roelke, R. Mancy, and S. Spatharis, "Lumpy species coexistence arises robustly in fluctuating resource environments," Proceedings of the $\mathrm{Na}$ tional Academy of Sciences, vol. 115, no. 4, pp. 738-743, 2018.

[14] H. O’Sullivan, P. Raumonen, P. Kaitaniemi, J. Perttunen, and R. Sievänen, "Integrating terrestrial laser scanning with functional-structural plant models to investigate ecological and evolutionary processes of forest communities," Annals of Botany, vol. 128, no. 6, pp. 663-684, 2021.

[15] C. M. S. Dufour, A. Herrel, and J. B. Losos, "Ecological character displacement between a native and an introduced species: the invasion of Anolis cristatellus in Dominica," Biological Journal of the Linnean Society, vol. 123, no. 1, pp. 43-54, 2018.

[16] L. F. Alvarez Leon, "AI and the capitalist space economy," Space and Polity, vol. 25, no. 2, pp. 220-236, 2021.

[17] C. S. Souza, P. K. Maruyama, C. Aoki et al., "Temporal variation in plant-pollinator networks from seasonal tropical 
environments: higher specialization when resources are scarce," Journal of Ecology, vol. 106, no. 6, pp. 2409-2420, 2018.

[18] Z. Zhang, C. Yan, and H. Zhang, "Mutualism between antagonists: its ecological and evolutionary implications," Integrative Zoology, vol. 16, no. 1, pp. 84-96, 2021.

[19] L. Mahaut, F. Fort, C. Violle, and G. T. Freschet, "Multiple facets of diversity effects on plant productivity: species richness, functional diversity, species identity and intraspecific competition," Functional Ecology, vol. 34, no. 1, pp. 287-298, 2020

[20] G. Louarn, R. Barillot, D. Combes, and A. Escobar-Gutiérrez, "Towards intercrop ideotypes: non-random trait assembly can promote overyielding and stability of species proportion in simulated legume-based mixtures," Annals of Botany, vol. 126, no. 4, pp. 671-685, 2020. 